\title{
"os dentes afiados da vida preferem a carne na mais tenra infância1": etnocartografar com olhos de besta
}

marcos ribeiro de melo 2 universidade federal de sergipe, brasil https:// orcid.org/0000-0003-3289-2528 michele de freitas faria de vasconcelos 3 universidade federal de sergipe, brasil https:/ / orcid.org/0000-0002-9013-6352 edson augusto de souza neto 4 universidade federal de sergipe, brasil https:// orcid.org/0000-0001-5043-9845

\section{resumo}

neste artigo, dispomo-nos ao exercício de uma etnocartografia de tela em agenciamento com o filme Beasts of the southern wild (2012) dirigido por Benh Zeitlin. Lançamo-nos numa experimentação fílmica que desembocou numa escrita a artistar e infantilar (nossos) modos de vida. Apostamos no cinema e na infância como possibilidades de ensaiar um gaguejar da linguagem para a criação de novos mundos e formas de viver. As imagens do cinema menos como representação, e mais como arte que se propõe à incompletude, à fissura, a um buraco nas aparências. A infância como exercício de diferenciação e de resistência às narrativas dominantes em um dado contexto. A infância como experiência limite da/na linguagem, a desnudar incansavelmente a condição humana frente ao mundo. Deste modo, acompanhando a personagem principal da trama, a pequena Hushpuppy, uma moradora de seis anos de idade da 'Ilha de Charles Doucet', tratada todo o tempo como "a Banheira", somos estremecidos pelas formas de vidas ali presentes, consideradas bestiais e não reconhecidas pelos homens citadinos. Hushpuppy, seu pai e amigos resistem às tentativas de destruição de suas existências pelas forças do Estado que tentam domesticá-los, imbuídos da lógica de que primitivos devem vir para civilização, assim como as crianças devem se tornar adultos.

palavras-chave: infância; cinema; etnocartografia de tela; bestas.

\section{"the sharp teeth of life prefer meat in the earliest childhood": an ethnocartography with beasties eyes}

\section{abstract}

in this article, we experience the exercise of a screen ethnocartography in agency with the film Beasts of the southern wild (2012) by the director Benh Zeitlin. We tested a film experimentation that led to a renewed writing (our) ways of life. We bet on cinema and childhood as possibilities for creating cracks and a stutter of language for the creation of new worlds and ways of living. In cinema images less as a representation, and more as art that proposes incompleteness, fissure, a hole in appearances. In childhood as an

\footnotetext{
1 Parte de um poema sem título de Paulo Leminski publicado no livro Quarenta clics em Curitiba no ano de 1976 (LEMINSKI, 2013, p. 19).

2 E-mail: marcos_demelo@hotmail.com

3 E-mail: michelevasconcelos@hotmail.com

4 E-mail: edson.asnt@gmail.com
} 
"os dentes afiados da vida preferem a carne na mais tenra infância": etnocartografar com olhos de besta

exercise of differentiation and resistance to dominant narratives in a given context. In childhood as a limiting experience of/in language, tirelessly exposing the human condition in front of the world. Thus, accompanying the main character of the plot, little Hushpuppy - a six-year-old resident of the "Charles Doucet Island", experienced as "the Bathtub" - , we are shaken by the forms of life there, considered bestial and not recognized by city humans. Hushpuppy, his father and friends resist attempts to destroy their existence by the forms of the state that try to domesticate them, imbued with the logic that primitives must come to civilization, just as children must become adults.

keywords: childhood; cinema; screen ethnocartography; language; beasties.

\section{"los dientes afilados de la vida prefieren la carne en la primera infancia": etno- cartografiar con ojos de bestia \\ resumen}

En este artículo, estamos dispuestos a ejercer una etno-cartografía de pantalla en agencia con la película Beasts of the southern wild (2012) dirigida por Benh Zeitlin. Nos embarcamos en un experimento cinematográfico que condujo a una escritura para artistar e infantilar (nuestras) formas de vida. Apostamos por el cine y la infancia como posibilidades de ensayar un tartamudeo del lenguaje para la creación de nuevos mundos y formas de vivir. Las imágenes del cine menos como representación y más como arte que propone la incompletitud, la fisura, un hueco en las apariencias. La infancia como ejercicio de diferenciación y resistencia a las narrativas dominantes en un contexto dado. La infancia como experiencia límite del/en el lenguaje, exponiendo incansablemente la condición humana frente al mundo. Así, acompañando al protagonista de la trama, la pequeña Hushpuppy, una niña de seis años residente de la 'Isla Charles Doucet', tratada todo el tiempo como "la Bañera", nos estremecen las formas de vida allí presentes, consideradas bestiales y no reconocidas por los hombres de la ciudad. Hushpuppy, su padre y amigos se resisten a los intentos de destruir su existencia por parte de fuerzas estatales que intentan domesticarlos, imbuidos de la lógica en que los primitivos deben venir para la civilización, así como los niños deben convertirse en adultos.

palabras clave: infância; cine; etno-cartografía de pantalla; bestias. 
marcos r. de melo; michele de f. faria de vasconcelos; edson augusto de souza neto

"os dentes afiados da vida preferem a carne na mais tenra infância ${ }^{5 "}$ : etnocartografar com olhos de besta

por um cinema e uma pesquisa infantiladores 6

Há uma potência própria à infância, há na infância o "ainda", como aponta Leminski (2013) em seu poema. Há na infância um exercício de diferenciação e de resistência às narrativas dominantes em um dado contexto e época. É quando ainda, o escavar de um tempo, o escapar de um espaço, uma revolta, um gesto disperso, infante, brinca com a "salmoura do dia a dia", dando densidade e intensidade ao cotidiano. Nossa aposta neste artigo é de que essa densidade e intensidade possam insurgir de um agenciamento entre arte cinematográfica e $\operatorname{artistagem~}^{7}$ da infância (CORAZZA, 2002; 2006), desencaminhando modos de ver, perceber e sentir. Para isto, dispomo-nos ao exercício de uma etnocartografia de tela em agenciamento com o filme Beasts of the southern wild (2012) dirigido por Benh Zeitlin. Com a película, acompanhamos a personagem principal da trama, a pequena Hushpuppy, uma moradora de seis anos de idade da 'Ilha de Charles Doucet', tratada todo o tempo como "a Banheira".

As argumentações a serem apresentadas neste escrito dependem, inicial e fundamentalmente, das concepções de infância, de cinema e de pesquisa com as quais nos agenciamos. $\mathrm{O}$ entendimento de infância assumido aqui não consiste naquele que advém de uma delimitação cronológica ou de etapa do desenvolvimento biopsicológico, mas, antes, numa certa forma de experiência limite da/na linguagem (AGAMBEN, 2005). Partimos da definição de Agamben (2005) que concebe a infância como marcada por uma 'negatividade constitutiva'. Segundo o autor, in-fans significa, fundamentalmente, 'não fala' uma negatividade que situa a infância entre os campos da linguagem e da experiência. Assim, concebemos a infância nestes termos: como aquilo que não

\footnotetext{
5 Parte de um poema sem título de Paulo Leminski publicado no livro Quarenta clics em Curitiba no ano de 1976 (LEMINSKI, 2013, p. 19).

${ }^{6}$ Sobre a ideia de infantilar, veja: KOHAN, Walter O. A infância da educação: o conceito devircriança. In:_. Infância, estrangeiridade e ignorância. Belo Horizonte: Autêntica, 2007, p. 85-98.

${ }^{7}$ Neologismo criado por Sandra Mara Corazza que diz respeito a uma experimentação de ordem poética, estética e política onde se trabalha nas fronteiras entre as disciplinas, os sujeitos e os não-sujeitos, os sentidos e os sem-sentidos, buscando-se o não-pensado do pensamento (CORAZZA, 2002;2006).
} 
"os dentes afiados da vida preferem a carne na mais tenra infância": etnocartografar com olhos de besta

é dotado de fala, aquilo que se encontra habitando limites do/no campo linguístico. Esse situar-se no ínterim entre a experiência e a linguagem implica um experimentum linguae - uma experiência com 'conceitos vazios sem objeto', com as palavras elas mesmas, sem um referente específico que não seja ela própria. Dessa forma, se consideramos que a linguagem constitui mundos e formas de viver, uma das principais consequências da condição infante é a revisão radical do 'comum', do gregário instaurado pela repetição da língua uma forma de organização da linguagem em uma gramática, ou, como diria Deleuze (1992), como um mapa político, uma palavra de ordem.

Nesses termos, podemos dizer que a condição infante de ausência da fala nos desperta para a relevância de pensar a estrangeiridade e o desnaturalizante das predefinições culturais que atravessam a infância (KOHAN, 2007). A estrangeiridade infantil é, assim, um terreno incerto demais para palavras de ordem, e o ato de inserir o infantil no registro linguístico pode ser visto como o ato de inseri-lo em relações de poder, de torná-lo sujeito aos comandos. Ainda assim, é precisamente essa tentativa de colonização do infantil a responsável por pô-la em contato com os 'conceitos vazios sem objeto' das próprias palavras de ordem. Por consequência, o colonizado e o colonizador não mantêm, nesses termos, uma dinâmica unilateral (AGAMBEN, 2005; OKINAWA, 1952).

A afirmação de que é preciso conceber a infância enquanto experiência significa dizer que o encontro com o infantil deve acontecer fora do campo das predefinições do que é a infância, desvinculando-se das suas definições biopsicológicas, traços de um desenvolvimento normal ou padrão esperado (VASCONCELOS, MELO e SOUZA NETO, 2018). Pode-se dizer que o tangenciamento das questões cronológicas, das etapas de desenvolvimento, das formas vigentes de enunciação dos corpos infantis, é uma tentativa de permitir que dimensões infantis políticas, deliberadamente excluídas, ganhem expressão e potência. A linguística e a infância comunicam-se, portanto, sob a égide de um desconhecido - de uma 'não fala', de uma exceção à ordem das relações com língua -, o qual só em um máximo de abertura e esforço conseguimos tatear (LARROSA, 2009; VASCONCELOS, MELO e OLIVEIRA, 2017; VASCONCELOS, MELO e SOUZA NETO, 2018). 
marcos r. de melo; michele de f. faria de vasconcelos; edson augusto de souza neto

O exercício é de pensar nos agenciando com linhas de fuga, politicamente propondo rastreios em vez de produções estagnadas - não temos um interesse em dizer 'o que é a criança', 'o que é a infância', ou, mais desnudadamente: 'o que deve ser a criança', 'o que deve ser a infância'. Nessa direção, uma certa forma de fazer-pensar cinema nos é particularmente valiosa - nos aproximamos da produção cinematográfica enquanto campo de experimentação e problematização, de reprodução e de modificação, dos discursos em nosso mundo (VASCONCELOS, MELO e SOUZA NETO, 2018). Esta forma de pensar se constitui a partir de imagens intensivas como uma forma de produção de pensamento que age como força dissociadora e que pode ser observada precisamente pela inexistência de um Todo pedagógico a ser exposto pelo filme (DELEUZE, 2005). Ou seja, um cinema que se propõe à incompletude, à fissura, a um buraco nas aparências - nesses termos, um cinema de uma negatividade constitutiva, um cinema infantilador.

Assim, a condição de in-fans, como experiência limite da/na linguagem, consistiria em uma forma de fazê-la variar. A arte, portanto, consistiria em um exercício de produção de linhas de fuga ao gregarismo linguístico. Deste ponto, lança-se um cinema que se apresenta como um exercício de criação, favorecendo um pensamento que se constituiria precisamente nas brechas, em um certo vazio dado pela cena. Um certo cinema disporia cenas intensivas, capazes de convocar uma desestabilização que emerge da desconexão com o encadeamento esperado, com uma infância e com um cinema esperado, este como transmissão pura de informações sobre uma dada infância pedagogizada (DELEUZE, 2005).

A aposta é, pois, produzir movimentos com imagens, menos como representação de um mundo e mais como afecção, a qual é “diferente de afeto ou sentimento que são emoções psicológicas" (ROLNIK, 2016, p. 10). Afecção entendida como "uma emoção vital que tem a ver com afetar, no sentido de tocar, contaminar, perturbar. É nesse sentido que pensamos numa artistagem infantil: escavação de um intervalo, um entremeio, uma experiência "'fora-dosujeito' ou 'extra-pessoal': é a experiência das forças que agitam o mundo 
"os dentes afiados da vida preferem a carne na mais tenra infância": etnocartografar com olhos de besta

enquanto corpo vivo e que produzem efeitos em nosso corpo, em nossa condição de vivente" (ROLNIK, 2016, p. 10).

Dada a coextensão entre as palavras de ordem e a linguagem (DELEUZE e GUATTARI, 1995), a desterritorialização e a reterritorialização dos objetos e dos atos de fala - suas mudanças de posição materiais e simbólicas - tornou-se necessário inventar estratégias metodológicas que nos permitissem navegar nesse âmbito político e linguístico. Para tanto, a proposta inicial de uma etnografia de tela, ou seja, de uma realocação do método etnográfico para o estudo das produções audiovisuais (BALESTRIN e SOARES, 2012; RIAL, 2004), deveria ser posta em termos também cartográficos (VASCONCELOS, MELO e SOUZA NETO, 2018). Isso porque, afastando-nos de automatismos simbólicos, não pretendemos descrever um mundo dado, ou, colocando em outros termos, as configurações subjetivas e as formas culturais instituídas. O que almejamos é acompanhar a vida ali onde ela se ensaia, se artista. $\mathrm{O}$ desejo que nos move a pesquisar é acompanhar processos de subjetivação, derivas nas paisagens subjetivas e culturais; traçar esboços de paisagens moventes, escavando um espaço bem ali entre a história e o devir, tempo em que se tece a diferença nos estratos histórico-culturais (PASSOS; KASTRUP; ESCÓSSIA, 2015).

A etnografia de tela consiste em transferir para o estudo das mídias as técnicas de análise originalmente utilizadas na etnografia convencional (RIAL, 2004; BALESTRIN e SOARES, 2012). Esse exercício implica uma dinâmica de vivência e registro marcada pela longa imersão no campo-filme, observação sistemática variada, seleção de cenas e descrição densa (BALESTRIN e SOARES, 2012; BALESTRIN, 2013). Em virtude das diferenças entre o campo etnográfico convencional e o campo-filme, há também a inclusão de categorias e técnicas mais comumente associadas à crítica cinematográfica, como a análise minuciosa das cores em cena, dos planos escolhidos, da montagem do filme, dos movimentos em cena e da forma como os personagens são apresentados e dispostos ao longo do filme (BALESTRIN e SOARES, 2012; BALESTRIN, 2013). Tal proposta metodológica mescla recursos do método etnográfico e recursos da crítica cinematográfica. Assumimos, entretanto, a composição de um campo 
marcos r. de melo; michele de f. faria de vasconcelos; edson augusto de souza neto

como rizoma, o que nos convoca a uma revisão dos princípios metodológicos assumidos e nos aproxima do método cartográfico (VICENTE e SILVA, 2018).

Dessa articulação entre-métodos, destacamos: (1) a necessidade de uma dinâmica atencional cartográfica, (2) de uma forma de descrição própria a uma linguística não representacional, e (3) de uma ética própria ao agenciamento com a alteridade menor, no sentido dado por Deleuze e Guattari (1995) - ou seja, daquilo que é a motriz da variação, do vir a ser. Uma dinâmica atencional cartográfica consiste basicamente em uma postura ao mesmo tempo concentrada e sem foco, permissiva ao desconhecido e às violações possíveis do preconcebido (KASTRUP, 2007). A cognição do cartógrafo é a abertura para o intempestivo, descrito em movimentos de rastreio, toque, pouso e reconhecimento atento que favorecem o agenciamento singular e a escuta, o tateio, das forças em jogo e das consequentes tensões, conforme a descrição de Kastrup (2007). Esses movimentos vão de uma abertura atencional concentrada, que se lança ao campo a fim de rastreá-lo, até o reconhecimento de fato de um objeto constituído pelas forças em curso, uma parada no movimento, o acompanhar um processo.

$\mathrm{O}$ rastreio seria justamente o gesto de varredura do campo que acompanha as suas transformações, uma abertura sem foco que permite o aparecimento de uma percepção háptica, o conhecimento do objeto. Tal conhecimento não é da ordem de uma organização cognitiva em figura e fundo, mas de uma constituição que acontece com tais componentes lado a lado, como em percepção direta. Segue-se o toque, como forma de um pequeno vislumbre, e o pouso, como a criação de um novo território, como reconfiguração do campo de observação. O reconhecimento atento, por sua vez, é, ele mesmo, a perturbação do sensório-motor, de maneira que este movimento, longe de nos convocar uma descrição pormenorizada de um objeto prévio, trata do encontro com novas e antigas formas constituídas nas forças daquele campo. Nesse ponto, há uma convergência metodológica direta com a etnografia de tela: variar o assistir no exercício do rastreio. Ver o filme de várias maneiras, variar a sua cor, a tela, a companhia, a velocidade, remover personagens da tela, experimentar a produção de novas narrativas, de novas conexões (BALESTRIN 
"os dentes afiados da vida preferem a carne na mais tenra infância": etnocartografar com olhos de besta

e SOARES, 2012), experimentar as tensões linguístico-políticas em curso (DELEUZE e GUATTARI, 1995).

Outra mudança diz respeito à perspectiva político-linguística, uma vez que esta aponta uma sobreposição entre a linguagem e a política que também convoca o rompimento com uma linguística representacional (DELEUZE e GUATTARI, 1995; VICENTE e SILVA, 2018). Esse abandono coloca o próprio pesquisador em uma condição mais ou menos limítrofe em relação a língua, uma vez que demanda que a sua abertura torne possível, em alguma medida, um tateio que permita que novas configurações, novas narrativas, sejam produzidas em contato com o in-fans em tela (VASCONCELOS, MELO e SOUZA NETO, 2018). Disso decorre que uma ética da escrita também é necessária, abandonando-se composições nas quais figuram ideias generalizantes e/ou totalitárias. Trata-se de considerar que conceitos previamente dados, comumente reproduzidos em nosso campo linguístico, podem não mais assentar-se adequadamente frente às desterritorializações possíveis do cinema; ou de que desterritorializações possíveis do cinema podem ainda não se assentarem nas formas de existência sustentadas por nosso campo linguístico (DELEUZE e GUATTARI, 1995).

Ao rompermos com a linguística representacional, o exercício de acompanhamento das forças em curso compreende uma noção de campo rizomática (DELEUZE e GUATTARI, 1995; KASTRUP, 2000). Tal concepção abandona o caráter hierárquico, tanto por conceber relações possíveis entre fenômenos de naturezas diversas - físicas, químicas e psicológicas, por exemplo -, quanto pelo abandono do caráter idealizado trazido pela ideia de representação (DELEUZE e GUATTARI, 1995). A ideia de uma representação ideal de algo nos levaria a incorrer na concepção de um ruído, como uma diferença dada pela falta ou excesso do objeto em relação ao seu ideal, aquilo que faz com que o objeto tenha sempre um déficit de perfeição. É nesse sentido que se fala de uma forma de descrição própria, pois esta abandonaria a suposição de objetos estruturados idealmente para pensá-los na constituição deles em suas conexões, no campo de forças imanentes que o constituem (SOUZA NETO et al., 2019). 
marcos r. de melo; michele de f. faria de vasconcelos; edson augusto de souza neto

Ainda que para pensar o método partamos de uma argumentação que inicia com as questões semióticas, o rizoma se impõe para além dessas cadeias: conecta-se às cadeias políticas, biológicas, sociais, econômicas, imagéticas etc., alargando a amplitude da análise. Se as universalizações dirigidas à infância assumem, em sua maioria, a noção de um deficit, de uma incompletude, e a questão 'o que falta à infância para que seja adultez' é recorrente (KASTRUP, 2000), a nossa busca é por uma afirmação positiva da infância, e tal postura linguística possui reverberações em outros campos. Ao assumirmos a ausência de voz da infância e ao tomá-la como forma de experiência, por exemplo, lançamo-nos à questão: 'o que perdemos ao escrutinar a infância sob as palavras de ordem, referenciando-a sempre à adultez?' . O exercício de pesquisa é, então, um exercício de encontro heterogêneo - empírico, ao modo dos autores - com um devir-criança e a consequente criação e transmutação (DELEUZE e GUATTARI, 1995).

Cabe, portanto, conceber ainda que a etnocartografia se situa em um movimento de virada em que conteúdo - o expresso - e expressão - a narrativa, a forma como se expressa - se constituem heterogêneos, mas intrincados (DELEUZE e GUATTARI, 1995). As expressões consistem, assim, em intervenções nos conteúdos "não para representá-los, mas para antecipá-los, retrocedê-los, retardá-los ou precipitá-los, destacá-los ou reuni-los, recortá-los de um outro modo" (DELEUZE e GUATTARI, 1995, p. 27), e são elas mesmas concebidas como corpos. Dessa maneira, concebe-se a possibilidade de desterritorialização advinda do movimento semiótico - um recorte maior, um recorte menor, uma outra perspectiva, uma nova definição - ou materiais eventos que desafiem as definições, que as alarguem, que obriguem a mudança semiótica. Nesse sentido, há uma relação de agenciamento entre regimes de signos e corpos que se dá em dois eixos: entre um agenciamento maquínico de corpos e um agenciamento maquínico de enunciação; e entre lados territoriais ou reterritorializados e picos de desterritorialização. Há, ainda, uma dinâmica própria entre formas molares - politicamente majoritárias, lógicas gerais de mundo - e moleculares - dos encontros singulares e das suas produções (DELEUZE e GUATTARI, 1995). 
"os dentes afiados da vida preferem a carne na mais tenra infância": etnocartografar com olhos de besta

É preciso, por fim, situar a etnocartografia de tela enquanto método em um certo horizonte etnográfico, dado que a articulação teórico-conceitualmetodológica é constituinte do rigor do próprio método da etnografia - uma questão deste campo de pesquisa que, à sua maneira, Peirano (1995) descreve longamente. Neste sentido, a etnocartografia de tela seria dotada de alguma heterodoxia, algo antecipada pelos esforços por uma antropologia pósestrutural eximiamente expressos na obra de Castro (2018), mais especialmente em seu exercício de releitura das experiências do xamã amazônico por meio do conceito de devir-jaguar - do totemismo imaginário do jaguar que o homem se torna sacrificialmente, e das transformações reais que igualmente se precipitam. A própria constituição do campo, assim, se situa sobre o conceito antirrepresentacional do devir, pois é o próprio devir "uma relação real, molecular e intensiva que opera em um registro outro que o da relacionalidade ainda apenas morfológica do estruturalismo" (CASTRO, 2018, p. 184).

Duas dobras, assim, expressam um caminho que leva à constituição da etnocartografia de tela como método de pesquisa e análise. A primeira delas, refere-se à própria concepção do cinema como um campo ao qual se pode dirigir o exercício da etnografia, ao que encontramos as análises de Rial (2004) e de Balestrin e Soares (2012), em suas apostas para uma releitura do método etnográfico que em certa medida remetem às análises fílmicas de Benedict e Mead durante a Segunda Guerra Mundial (HIKIJI, 1998). Neste sentido, o direcionamento metodológico encontra-se com a etnografia ao propor uma análise antropológica do filme, um estudo das telas em sua quase onipresença no contemporâneo e na potencialidade do cinema como veículo de palavras de ordem de uma língua e uma cultura. Esta direção nos aponta, ainda, tanto a adaptação do método etnográfico somado à crítica cinematográfica quanto os próprios exercícios de análise minuciosa sobre a leitura das sinopses, a tomada de notas das cenas que despertam atenção especial pela repetição e diferenciação dos assuntos, as expressões, detalhes e técnicas que remetem a um contexto cultural que vaza a tela (HIKIJI, 1998; BALESTRIN e SOARES, 2012). A segunda dobra, por sua vez, remete à própria aproximação com o método cartográfico, com qual nos encontramos intrincados em nossas 
marcos r. de melo; michele de f. faria de vasconcelos; edson augusto de souza neto

concepções de campo (VICENTE e SILVA, 2018; CASTRO, 2018) e de atenção (KASTRUP, 2007). Neste sentido, o exercício etnocartográfico consiste no acompanhamento de efeitos-subjetividade, na construção de um mapa rizomático que se constitui nas zonas de problematização de paisagens culturais naturalizadas, ali onde se germinam outras formas de vida; um mapa interessado no processo de formação de mundos (ROLNIK, 2006). Um mapa no qual qualquer ponto pode ser conectado a outro e deve sê-lo; um mapa que ultrapassa o linguístico e se conecta a modos de codificação diversos; que se concebe na multiplicidade que para crescer muda de natureza e na possibilidade de ruptura a-significante, como Vicente e Silva (2018) apresentam mais didaticamente em seu texto.

Uma etno-cartografia de tela, assim, repousa subitamente em um método de pesquisa e análise que se dirige à tela como campo; que, para isto, a constitui como campo rizomático e não representacional, buscando acompanhar devires no encontro com a tela e as conexões desta tela com a diferença que também a ultrapassa. Para isso, se vale do uso de técnicas de descrição densa, registro em diário de campo, observação sistemática variada, longos períodos de contato com a tela e escolhas de cenas em sua constituição. Consiste, portanto, em uma aposta metodológica que se firma em esforços recentes por uma antropologia pós-estrutural (CASTRO, 2018) ao mesmo tempo em que se aproxima do método cartográfico e sua geografia dos devires em uma tentativa de mergulho na experiência do campo-tela em sua etnocartografia própria (VASCONCELOS, MELO e SOUZA NETO, 2018; SOUZA NETO et al., 2019).

O encontro com uma infância singular, o exercício de se distanciar do molar para acessar o molecular consiste, assim, em peça constituinte do método proposto. Nesses termos, então, a ideia é a de um método que, em sua descrição e análise densa, em sua produção de experiências e contato com experimentações, produza desterritorializações, produções moleculares que influenciem e potencializem narrativas infantis até então contidas e negativizadas em função de uma racionalidade molar, teleológica.

introdução a uma irrazoabilidade feroz 
"os dentes afiados da vida preferem a carne na mais tenra infância": etnocartografar com olhos de besta

O primeiro contato com Beats of the Southern Wild (2012) despertou para uma sensação bastante específica. Era-lhe possível abordar a ferocidade e a irrazoabilidade em um mundo sempre retratado em uma referência ao seu apocalipse sem perder a sutileza necessária da sensação de encantamento. $\mathrm{O}$ filme parecia encontrar a sua síntese na sua própria cena de abertura, quando a protagonista, Hushpuppy, corre segurando grandes fogos de artifício, apontando para um espaço entre o risco e a composição de uma obra de arte.

O filme conta a história de Hushpuppy, uma garota que vive na 'Ilha de Charles Doucet', tratada todo o tempo como 'A Banheira', o lugar com mais férias no mundo. Às margens da Banheira, estende-se uma cidade enorme, quase desconhecida e profundamente renegada pelos personagens. Esta situação se complica quando emergem no enredo a doença de Wink, pai de Hushpuppy, e uma violenta tempestade que leva água salgada às águas da Banheira. A crise ambiental devasta a fauna e a flora, e se estende até a própria doença de Wink, que se desenvolve intrincada em outros fenômenos naturais, sinalizando uma união radical entre o homem e o 'seu' ambiente.

Em uma tentativa de corrigir o problema levando mais água doce à Banheira, os moradores explodem a barragem que os separava da cidade. A explosão acaba atraindo a atenção das forças do Estado, que os impõe o cuidado de serem retirados da área de risco e serem inclusos nos serviços de saúde. A inclusão (para conter o risco) arrisca todo o princípio que sustenta a Banheira e as formas de vida humana que a habitavam, desafiando a sua conexão direta com a natureza e uma forma outra (não citadina) de lidar com a insalubridade ou a morte. Com o agravamento da doença de Wink, entretanto, os desafios de uma outra forma de existência parecem levados à radicalidade aceitar a inclusão no sistema de saúde é, também, aceitar que os modos de vida dos moradores da Banheira sejam inclusos na cidade?

Diante das questões sobre a doença do pai e a ausência da mãe, Hushpuppy avista recorrentemente grandes bisões que caminham de longe para se encontrarem com ela. Cada vez mais próximos, os bisões vão de figuras imaginárias até a concretude quase completa da sua existência. Foi sobre essas 
marcos r. de melo; michele de f. faria de vasconcelos; edson augusto de souza neto

figuras, que convocavam um descompasso com a realidade do filme, que, inicialmente, uma atenção cartográfica se deteve.

Princípio: todo animal é feito de carne

"Carne. Carne. Carne. Todo animal é feito de carne. Eu sou carne. Vocês são carne. Tudo é parte do bufê do universo". Os olhos de Hushpuppy e das outras garotas acompanham a mulher que fala enquanto passeia detrás de lagostasamericanas empilhadas em uma mesa de madeira. Caminhando, ela nos permite ver uma gaiola, uma coruja, os rostos curiosos das alunas a partir de uma outra perspectiva... Hushpuppy encara a coruja nos olhos. Mantém o rosto sério. A mulher pisa com um dos pés em uma cadeira e exibe a coxa onde tem tatuada uma pintura rupestre: três homens lutam contra seres enormes com cascos e chifres.

"Este aqui é um bisão, uma criatura malvada e feroz que andava pela face da Terra quando o homem ainda vivia nas cavernas" - vemos a tatuagem ainda mais de perto, menos desfocada, e a garota abre os lábios discretamente, como se estivesse pasma com a intensa explicação, com os poderes dos enormes bisões, com a impressão epidérmica daquela figura gravada permanentemente na coxa. "Devoravam os bebês da caverna diante dos seus pais da caverna, e os homens da caverna não podiam fazer nada", segue a mulher, agora se esgueirando performativamente por trás de aquários vazios com plantas secas dentro. " $E$ os homens da caverna não podiam fazer nada, porque eram muito pobres e muito pequenos!" Então ela se põe ereta e continua: - "Quem de vocês acha que os homens da caverna ficavam por aí chorando como menininhas?".

A professora joga novamente sobre a mesa uma lagosta que havia caído, e apressadamente, com gestos de revolta que se mesclam aos poucos com gestos de cuidado, se dirige a um mapa enquanto explica: "É melhor pensarem bem, porque um dia desses a estrutura do universo se alterará, as calotas polares derreterão, o mar subirá, e tudo que está ao sul da barragem ficará submerso. É melhor que aprendam a sobreviver agora!".

O fim do mundo relatado pela professora é, também, uma tentativa de desnudamento das forças naturais que se estendem por sobre as existências 
"os dentes afiados da vida preferem a carne na mais tenra infância": etnocartografar com olhos de besta

humanas. Este contato de Hushpuppy com circunstâncias-limite parece delinear um constante desnudamento da condição humana frente ao mundo. De fato, não assistimos a um apocalipse absoluto no filme, como parece sugerir a fala da professora, mas as palavras durante a aula mesclam-se profeticamente aos acontecimentos posteriores do enredo.

Com a tempestade que se abate sobre a Banheira e que dá início ao segundo ato do filme, a água sobe, levando o sal do mar para a Banheira, o que destrói todas as fontes de alimento. A violência dos ventos acaba deixando alguns amigos desaparecidos. Os âmbitos da crise são ecológicos - pois é um desastre ambiental que acompanha o enredo do filme -; políticos - pois a resistência dos moradores é a aposta em uma forma de existência paralela à cidade capitalística que cresce ao lado -; familiares - pois se sucede à ausência da mãe de Hushpuppy a morte inevitável do seu pai, atravessada pela falta de alimento e pelo poderio estatal -; fisiológicos - pois se abate sobre a carne dos animais, sobre os tecidos das árvores -; e inclusive linguísticos - pois a fala dos médicos é molar, formal, e dotada de poder capaz de disparar forças policialescas vendidas sob a pele do cuidado da saúde para limitar as ações dos moradores da Banheira.

De fato, “o rizoma não é de origem linguística, [...] se conecta a modos de codificação diversos, cadeias biológicas, políticas, sociais, econômicas e culturais" (VICENTE e SILVA, 2018). Os bisões que atravessam de diversas formas os eventos do filme, ora como pinturas, ora encarnados, são, assim, simultaneamente reflexo e prenúncio dos acontecimentos, em um encadeamento de fatores que desenvolve e apresenta uma cosmologia singular da Banheira: tudo está brutalmente conectado, toda a vida é carne. Deleuze e Guattari (1995, p. 64), recorrendo a descrições de Levy Strauss, tratavam de uma cultura dotada de uma conexão igualmente radical:

É que na verdade, para um Hopi, tudo está ligado: uma desordem social, um incidente doméstico, invocam o sistema do universo cujos níveis são unidos por múltiplas correspondências; uma reviravolta em um plano só é inteligível, e moralmente tolerável, como projeção de outras reviravoltas, afetando outros níveis. 
marcos r. de melo; michele de f. faria de vasconcelos; edson augusto de souza neto

É a partir desta visão de mundo, que apresenta uma conexão entre tudo aquilo que o compõe, que Hushpuppy entende o Todo como uma grande máquina. Entende, assim, que os desastres que ela presencia se dão por conta de uma peça que, pequena ou grande, deixara de funcionar direito. Isto, em um mundo que se apresenta na sua radicalidade corporal, a carne, é ainda mais relevante.

Uma certa perspectiva de ambientalismo emerge na medida em que o filme parece convocar a todo o tempo a cidade e a sua interferência no ambiente, em contraste com o cuidado minucioso de Hushpuppy com os pequenos detalhes que poderiam causar aquele problema. A cidade é campo dedicado aos doentes e frágeis, que, fragilizando e fazendo fragilizar, tenta constituir, à parte da natureza e ao custo desta, uma forma insalubre e dependente de vida - uma vida frágil (FERNANDES, 2011). É nesse sentido que Hushpuppy e Wink ironizam os homens citadinos que são como bebês, que vivem em aquários vazios, que têm medo da água e que se ligam à parede quando estão doentes (fazendo alusão aos fios e tubos dos aparelhos hospitalares).

A ferocidade dos moradores da banheira, traço que os permite levar ao limite a integração com a natureza, bem como a sobrevivência em disputa brutal com a cidade ao lado, é o que os diferencia do adestramento do homem comum, gregário, citadino. A fala, entende Hushpuppy, é também de caráter carnal. Ouvindo o bater dos corações dos animais, caminhando entre eles calçada em galochas enormes, a voz da garota narra: “Todos os corações batem e bombeiam. E conversam de formas que não entendo. Na maioria das vezes, provavelmente dizem: 'Estou com fome.', 'Quero fazer cocô.'. Mas às vezes conversam em código'.

O contato direto com as forças que constituem o mundo em suas questões de vida e morte, no fim do mundo e na imanência radical da vida, pouco ou nada tem a ver com o fim de uma infância ocidentalizada, o fim de uma inocência infantil, mas, sim, com a existência de uma condição menor, que beira o incompreensível aos moradores da cidade. Se torcermos o conceito de Agamben (2005) para falarmos de uma dimensão de in-fans em Hushpuppy - 
"os dentes afiados da vida preferem a carne na mais tenra infância": etnocartografar com olhos de besta

nesse caso, uma fala incompreensível ou um âmbito de 'não fala' em relação à cultura da cidade - falamos precisamente pela condição de estrangeira, pela condição de quem habita um devir-minoritário, que não se confunde com a ideia vigente de minoria frágil a ser incluída na lógica social vigente para continuar excluída, porém organizada e classificada como inferior. A quem habita um devir-minoritário, por consequência, o estranhamento do mundo da cidade, da sua forma de falar e de produzir um mundo, é a expressão mais espontânea. Estar em contato radical com o mundo, assim, é, antes, o contrário de uma 'adultez': a desnaturalização das instituições (LARROSA, 2009) e a reterritorialização que se precipita em um novo campo (DELEUZE e GUATTARI, 1995).

Certamente a escatologia e a cultura própria à Banheira nos é, também, distinta. A concepção daquele ordenamento de mundo é tão improvável à nossa lógica quanto os bisões que marcham para encontrar a protagonista. O encontro entre eles surpreende, como se o filme enviasse uma mensagem que reitera o que dizia até então, de que não há metáforas em jogo, de que há um jogo carnal em tela, abertura para a alteridade e a desestabilização que ela nos convoca. À parte das questões mágicas e das conexões menos óbvias, e à parte de preconcepções que se encadeiam aos desejos pela oferta de cuidado aos 'pobres moradores da Banheira', avistam-se questões outras. Não estaríamos ignorando os riscos de uma insalubridade mais difusa e mais persistente em nossa própria sociedade? O risco enorme, mas discreto, das paredes de vidro de um aquário? Ou de um condomínio? Ou da campânula de vidro linguístico-corporal que envolve e produz a vida citadina?

Outros princípios: existe mais de uma forma de coesão

Ao comando de um grito da protagonista, várias meninas correm mar adentro. Nadam com alguma dificuldade. "Vamos lá!", grita Hushpuppy. Em um enquadramento maior da tela, as garotas são como um pequeno aglomerado de pontos distantes da praia, seguindo agarradas em uma pequena boia. Um barco de faróis acesos toca a sirene anunciando a presença. As garotas sobem ao convés, de onde veem ao alto um homem de meia-idade trajando 
marcos r. de melo; michele de f. faria de vasconcelos; edson augusto de souza neto

chapéu, colete, calças e sapatos pretos. Hushpuppy e as meninas olham para o homem, e seus olhares e caretas - olham contra o sol - se distribuem entre o desafio e a curiosidade. A protagonista estufa o peito: "Vou com minha mãe". Apoiado nas barras de proteção, a resposta do homem é pontual e ambígua: "É um bom lugar para ir".

O vento soprando os cabelos das garotas de pé, o barco velho e enferrujado - Grumpy, escrito no convés -, o horizonte se apresentando no entre das coisas, o mar, agora parte da própria cena atual.

Na cena seguinte, vemos Hushpuppy conversando com o homem do barco: "Para onde vamos?", pergunta a garota. "Não importa, querida. Este barco a levará exatamente aonde deve ir. É desse tipo de barco. Quer um biscoito de frango?". Hushpuppy nega acenando com a cabeça. "São bons pra você. Eu os tenho comido a vida toda. Conservo as embalagens no barco para lembrar quem eu era quando comi cada um deles", argumenta o homem sem persistir. As embalagens de papel cobrem o chão de branco e vermelho: "O cheiro me faz me sentir coeso...". "Eu quero ser coesa", a garota interrompe discretamente, falando sem alterar a postura. "Claro que você será, querida. Não tenho a menor dúvida", o homem responde.

A fuga de Hushpuppy para o mar, junto às outras meninas, acontece quando o seu pai retorna da cidade, ainda doente, para morrer em meio à comunidade da Banheira. Na narrativa fílmica abre-se uma brecha temporal na qual a garota se lança em uma aventura paralela à morte do seu pai, uma busca pela sua mãe, que parece encarnada na cozinheira do barco. Em meio às festas, a placa diz:

\section{CAMPOS ELÍSIOS}

\section{BARRACA DO BAGRE FLUTUANTE}

\section{GAROTAS, GAROTAS, GAROTAS}

Em que sentido se fala de uma coesão em meio àqueles biscoitos de frango? Em que sentido Hushpuppy se lança mar adentro junto às suas amigas enquanto a doença do seu pai avança? Em que sentido avistamos bisões avançando sobre casas, mares e terras sem hesitar entre as cenas que mostram a protagonista e seus dilemas? 
"os dentes afiados da vida preferem a carne na mais tenra infância": etnocartografar com olhos de besta

O acontecimento da morte do pai de Hushpuppy se apresenta como um profundo desestabilizador das estruturas a partir das quais ela compreendera o mundo até então. $\mathrm{O}$ sentido avistado é próximo às questões que Norbert Elias (2001) dispõe ao afirmar que inúmeras esquivas ao conhecimento da morte são usadas quando esta aparece. A morte, então, fenômeno inscrito no limite literal da carnalidade, estaria ainda, para o homem, em um campo do sentido, em uma política da sua fala (AGAMBEN, 2005; PELBART, 2008). Aqui, desta forma, não é a morte em si o problema, mas o conhecimento que a prenuncia, e do qual somente o humano seria capaz. É nesse sentido que se diz que

a mosca presa entre os dedos de uma pessoa luta tão convulsivamente quanto um ser humano entre as garras de um assassino. Mas os movimentos defensivos da mosca quando em um perigo mortal são um dom não aprendido de sua espécie [...]. Os seres humanos sabem, e assim a morte se torna um problema para eles (ELIAS, 2001, p. 11).

Ao homem morador do barco que leva "exatamente aonde deve ir", que tipo de coesão o cheiro dos biscoitos de frango poderia trazer? É preciso apostar em algum nível: ao morador do fluxo, o cheiro que o lembra daquilo que foi enquanto comeu cada um daqueles biscoitos, deveria, de fato, ser de grande valor - o sinal que salienta a temporalidade da sua existência e que constitui a sua memória no mar. A sua estratificação necessária (DELEUZE e GUATTARI, 1995).

Com isso, se quer dizer que a forma com que a garota - e, no limite desse pensamento, os moradores da Banheira - estabelecem a sua relação com o mundo constitui também um estrato, uma organização do mundo (DELEUZE e GUATTARI, 1995). É esta coesão, este processo de organização, em que Hushpuppy se lança para jogar com as minúcias da constituição de uma coesão para si própria. É, possivelmente, este movimento de reterritorialização que podemos tratar de forma positiva como uma certa 'adultez', destacando, entretanto, que certamente não existem empecilhos para que tal transvaloração seja incompreensível à comunidade na qual se situa.

Dito de outra forma, se consideramos que a condição de 'in-fans' é incompreensível a uma certa gramaticalidade, à língua de uma certa comunidade e a forma como esta língua constitui o mundo, podemos identificá- 
marcos r. de melo; michele de f. faria de vasconcelos; edson augusto de souza neto

la com a variação do devir desta comunidade (AGAMBEN, 2005; DELEUZE e GUATTARI, 1995). Por outro lado, ao falarmos de uma certa adultez, uma condição de 'fans', nos deparamos com ela em ao menos duas formas. A primeira enquanto estado maior, majoritário e estratificado - identificado com o território - e a segunda enquanto estado de variação de um movimento identificado com a reterritorialização. O sentido e a forma de coesão, a organização do mundo e de si, uma nova gramaticalidade, assim, é um feito projetado por Hushpuppy cuja sutileza e discrição encontra-se expressada na sua fuga como forma de lidar com a doença e a morte do seu pai.

É preciso destacar o quanto, aqui, demonstra-se a ausência de uma identificação entre a não fala e a idade cronológica. $O$ conflito ocorre simultaneamente entre o nominável e o inominável através do mesmo corpo, e tais compostos, heterogêneos entre si, convocam movimentos de ida e vinda, de desterritorialização e reterritorialização (KOHAN, 2007).

A cidade é uma forma de estratificação das possibilidades, a Banheira, também. As diferenças e desafios que se dispõem e a capacidade de abertura dessas estratificações para formas lisas e variações contínuas são questões a serem levadas em consideração. Mas o movimento, em seu limite, é necessário e inevitável, acompanhando-se dos exercícios de permanência: “Este barco a levará exatamente aonde deve ir. É desse tipo de barco. Quer um biscoito de frango?"

Meio: a carne não é razoável, nem coesa

Seu pai tem medo que você se perca na cidade má e misteriosa Que ele mesmo fez e desconhece Você tem medo que seu pai se perca na cidade má e misteriosa Que você mesmo fez e desconhece Seu pai não quer que corra o sangue dos filhos nos túneis da cidade má e misteriosa Você não quer que corra o sangue do pai nos túneis da cidade má e misteriosa

E a cidade misteriosamente cresce Pacto de sangue que todos fizeram e desconhecem (JARDS MACALÉ, 2018).

Parte da sensibilidade com a qual nos deparamos ao entrar em contato com a tela tratava da relação entre os modos de vida dos moradores da Banheira e da cidade. Dizia respeito ao contraste estabelecido entre uma forma 
"os dentes afiados da vida preferem a carne na mais tenra infância": etnocartografar com olhos de besta

de vida capitalística, pautada no sobrevivencialismo como forma de saúde, e uma vida outra, pautada em um hedonismo que comporta a vida e a morte como fenômenos não opostos. As escolhas estéticas do filme parecem apontar para isso na composição de cenas sutis, delicadamente dispostas, mescladas a cadáveres de animais mortos e à flora nascente. Os gestos de cuidado e de ferocidade da professora na primeira cena anteriormente descrita, ao contar as histórias dos bisões, parece resumir o conteúdo trazido pelas escolhas estéticas do filme. Apesar de tal beleza, há uma igual relevância no pensamento que se dirige para os riscos da radicalidade da carne, sobre o qual se debruça este tópico.

Antes de habitar a distinção marcada entre o espírito capitalístico da cidade e a carnalidade irrazoável da Banheira, entretanto, é necessário habitar uma certa vizinhança deste pensamento. Trata-se, de certa forma, de desnaturalizar os cuidados da cidade para apresentar-lhe os seus riscos, e de pensar a cidade a partir dos princípios que parecem emergir dos modos de vida da Banheira.

É nesse sentido que os aforismos de Nietzsche $(1886 / 2008)$ sobre a possibilidade de criação de algo para além do homem é essencial, e denuncia toda uma estruturação complexa de uma décadence da sociedade ocidental. Do complexo conjunto argumentativo do filósofo, recortamos a sua preocupação com o estreitamento das possibilidades provocado pela negação da vida neste mundo, bem como a expressão da agressividade como condição constituinte do humano.

É desta condição dos últimos homens que falamos, daqueles que se arrastam no fim da sua existência, e prolongam a sua agonia a todo custo, imersos nos prazeres diários - o Homo Otarius (PELBART, 2008). É precisamente o oposto disso que encontramos quando Hushpuppy fala sobre os pedidos de Wink: "Papai dizia que, se ele ficasse muito velho para beber cerveja ou pegar bagres, eu devia colocá-lo no barco e colocar fogo, assim ninguém poderia ligá-lo na parede". O texto de Pelbart (2008) levanta, assim, uma questão essencial a esta problemática:

E se, ao nos concentrarmos na simples sobrevivência, mesmo quando é qualificada como 'uma boa vida', o que realmente 
marcos r. de melo; michele de f. faria de vasconcelos; edson augusto de souza neto

perdemos na vida for a própria Vida? . [...] Não vale mais um histérico verdadeiramente vivo no questionamento permanente da própria existência que um obsessivo que evita acima de tudo que algo aconteça, que escolhe a morte em vida? (PELBART, 2008, p. 6-7).

Retomando a cidade: sendo ela uma configuração de estreitamento das possibilidades de vida, estaria fora da violência e da natureza? O momento em que os agentes sanitários adentram os barracos, capturam e integram os moradores aos serviços de saúde, e depois esforçam-se em adequá-los ao modo urbano, seria socialmente menos brutal do que a tempestade?

Ao assumir que a cidade consiste em uma forma menos brutalizada da vida, em um exercício que deveras permite um distanciamento da violência e a preservação do razoável, logo nos deparamos com o fato de que qualquer forma de abstenção mútua e total da violência recai "como aquilo que é: como vontade de negação da vida, como princípio de desagregação e declínio" (NIETZSCHE, 1886/2008, p. 2010, grifo dos autores). Por este caminho, encontramos a figura dos últimos homens, deparamo-nos com a formação persistentemente reativa em que a gramaticalidade dispõe o mundo em um conjunto de forças que rege corpos dominados, em um estreitamento constante das perspectivas das formas de existência, a redundância das palavras de ordem (DELEUZE e GUATTARI, 1995).

Por outro lado, se é possível compreender a cidade como forma de configuração das forças agressivas, de uma configuração que, não menos brutal que a Banheira, é, ainda assim, heterogênea, este outro caminho desvela algumas possibilidades da cidade enquanto potência, pois aponta, nela, mais de uma possibilidade de coesão, mais de uma configuração possível dos estratos linguísticos (DELEUZE, 2005; DELEUZE e GUATTARI, 1995). Sob esta perspectiva, a carne, como aquilo que dá corporalidade, que corresponde ao situar-se do homem no plano de imanência, é o que constitui os corpos urbanos. No limite, portanto, tais homens seriam capazes da criação de novas organizações frente à irrazoabilidade das forças em curso no mundo, o rompimento da ordem da gramaticalidade linguística, da dobra na gramaticalidade que os constitui. A abertura às possibilidades contadas pela Banheira em sua singularidade, a criação de novos valores, o trato com aquilo 
"os dentes afiados da vida preferem a carne na mais tenra infância": etnocartografar com olhos de besta

que perde o nome, que é discrepante ou irrazoável - os moradores à parte da cidade, a morte do pai - podem ser vistos, enfim, não como a necessidade de abandono da cidade, mas como forma de abertura desta para novas formas de coesão frente à irrazoabilidade da carne ou, como ainda diria o filósofo, apostando no corpo como a grande razão (NIETZSCHE, 1883/2011).

Fins em meios: a marcha dos bisões (o intempestivo em dois tempos)

Quatro bisões emergem das águas. Quatro garotas voltam do mar. Os tremores no chão contam a chegada dos grandes monstros que eram anunciados desde o princípio do filme. As garotas mantêm a marcha. A aceleram ao som dos tremores. Ao fundo de Hushpuppy, pela primeira vez em uma única cena, estão os bisões - javalis enormes com grandes chifres. A garota mantém a marcha, Wink está morrendo.

Quando, com esforço, o pai olha para Hushpuppy, atrás dela o maior dos bisões se aproxima. A garota se vira. Não temos mais nenhuma trilha sonora. $\mathrm{O}$ monstro aproxima o seu focinho, e a sua respiração soa tão alta quanto os tremores no chão que indicavam os seus passos. Wink também parece vê-los. A tela nos mostra os olhos negros da criatura, até que os bisões se ajoelham diante da garota. "Vocês são meus amigos, de certo modo. Tenho que cuidar dos meus". Os bisões recuam. A garota atravessa o grupo de pessoas, a vigília por Wink. Adentra o cômodo. Abre um pequeno recipiente de isopor. Alimenta o seu pai com um pequeno biscoito de frango. "Muito bom. Nada de chorar, ouviu?". "Nada de chorar", responde Hushpuppy.

Nietzsche $(1883 / 2011)$ fala da criança como a última das três metamorfoses do espírito. Do homem comum, que não se deu conta do absurdo, que se arrasta pelas normas comuns; do leão, que, tendo questionado as regras, lança-se do 'tu deves' para o 'eu quero', mas ainda não despertou para a revolta prática; e da própria criança, que cria os seus próprios valores em espontaneidade, em uma forma de brincadeira, de jogo. Mas em que sentido isso nos permite pensar a postura de Hushpuppy frente a morte do seu pai?

A 'carnalidade', quando identificada como o âmbito essencial da cosmologia da Banheira, é aquilo que se abre para a vontade de potência, para a 
marcos r. de melo; michele de f. faria de vasconcelos; edson augusto de souza neto

indeterminação e a conexão mais imediata com o mundo e os seus riscos. A carne, assim, identificaria-se com o plano do corpo ou da imanência (DELEUZE e GUATTARI, 1995), tendo consigo uma dimensão da imprevisibilidade que desafia quaisquer gramaticalidades que se pretendam representacionais - como contar a morte? O intempestivo, como aquilo que se desorganiza, que bifurca, habitaria este âmbito, daquilo que age contra o tempo, da análise (do grego análysis, ana+lýein, para cima + soltar, afrouxar, decompor) que bifurca a história (DELEUZE, 1990).

Certamente a morte não é um rompimento com o aspecto da coesão, mas uma aposta limite na coesão daquela vida. É nesse sentido que se pode falar na necessidade de transformações das gramaticalidades que devam convocar a carne, os corpos, a uma vida que mereça ser vivida (NIETZSCHE, 1883/2011; PELBART, 2008). É possível deduzir, assim, que a morte, ao contrário da negação da vida, é a sua aposta limite, e que, por consequência, há uma relação quase direta entre esse fenômeno em suas diversas manifestações e o modo como uma vida se apresenta em uma determinada cultura.

Para um pensamento dirigido às diferenças colocadas no filme, bem como entre a cidade e a Banheira, existiriam ao menos dois aspectos do intempestivo que colocariam em análise a trama do filme. $\mathrm{O}$ primeiro diria respeito à sua potência como força motriz do desenvolvimento de novas gramaticalidades e de novas formas de vida e de coesão do mundo, enquanto o segundo diria respeito à sua posição no âmago da existência humana, especialmente ali onde a gramaticalidade encontra o seu limite na falta - na condição infantil - ou no seu limite do excesso - na condição de moribundo antes da morte física.

Certamente, a gramaticalidade compõe a carnalidade, na medida em que habitariam um plano em comum, indistinto, e, coeso ou não, implicado diretamente com a vida e as formas de viver. Nesse sentido, a Banheira consiste em uma perspectiva singular sobre o mundo, e Beasts of the Southern Wild (2012) acaba por consistir em um avanço por questões brutais da existência através de uma nova ótica. Nesta ótica, os bisões marcham de fato ao lado de Hushpuppy, eles são a novidade nascente, o que está aquém e para além da fala, o devir, e 
"os dentes afiados da vida preferem a carne na mais tenra infância": etnocartografar com olhos de besta

habitam um espaço linguístico que lhes é próprio. Cindem, dessa forma, a realidade que nos é apresentada a partir da busca de uma nova coesão ante o moribundo hedonista e a criança que brinca com os novos valores.

Os fins a que se dispõem o filme, entretanto, seriam precisamente fins em meios, na medida que correspondem a movimentos que apontam direções, mas que não fecham soluções universais. Haveria a possibilidade da invenção de uma nova vida na cidade?

O maior equívoco possível a ser assumido, a premissa da qual, partindose, nada se resolve, nada se caminha, é aquela que é carregada pelo título recebido pelo filme em sua versão brasileira, que parece apontar para a necessidade de um sonho de Hushpuppy, um sonho capitalístico da 'Indomável Sonhadora'. Talvez, antes, devêssemos lançar questões sobre outros sonhos possíveis, sobre outras formas de vida possíveis aos moradores da cidade. Sim, é preciso politizar/infantilar os (nossos) sonhos!

\section{(In) conclusões}

Retomemos com o que iniciamos: há uma potência própria à infância...

os dentes afiados da vida preferem a carne na mais tenra infância

quando as mordidas doem mais a deixam cicatrizes indeléveis quando o sabor da carne ainda não foi estragado pela salmoura do dia a dia

$$
\begin{array}{r}
\text { é quando } \\
\text { ainda se chora } \\
\text { é quando } \\
\text { ainda se revolta } \\
\text { é quando } \\
\text { ainda }
\end{array}
$$

(LEMINSKI, 2013, p. 19).

Por meio desta experiência fílmica e escrita, levantaram-se questões sobre as possibilidades de formas outras de existências em meio aos regimes capitalísticos contemporâneos, habitando a barriga do monstro, como diria Donna Haraway (2009). Acionando um conjunto de conceitos em relação ao campo-tela, realizaram-se aproximações entre a pragmática linguística de Gilles 
marcos r. de melo; michele de f. faria de vasconcelos; edson augusto de souza neto

Deleuze e a condição de in-fans como condição disruptiva em relação às instituições preconcebidas em um dado momento histórico. A revisão de uma certa moral/vida maior em relação a outras formas menores de vida também foi um resultado importante.

Hushpuppy, assim como os moradores da ilha, em sua resistência aos modos capitalísticos e urbanos de vida, em seus arredores, mostram-se em suas existências bestiais e invisíveis, sem notoriedade, como "um infortúnio de vidas cinzentas para a história e que se desvanecem nos registros porque ninguém as considera relevantes para serem trazidas à luz" (LOBO, 2015, p. 13). Ao mesmo tempo, por serem criaturas incompreensíveis, "criaturas com entranhas" (LEMINSKI, 2013, p. 14), inábeis e inacabadas, estranhas ao círculo familiar citadino, imprecisas para a classificação, elas também correm perigo. Bestasferas precisam ser domesticadas, primitivos devem vir para civilização, crianças devem se tornar adultos. Como feras são inconcebíveis para as formas e as ordens do mundo (neste precisam ser incorporadas como/que nem bestas) correm perigo por possuírem as bordas de seus corpos como névoa:

São seres inumanos, quase humanos, passíveis de dissolução, porque vulneráveis a serem outros, como nuvens, névoas compostas e decompostas por outras matérias. Incompletude produzida por efeitos de encontros, entrelaçamentos, experimentações. Não salvam como os santos, não possuem nenhuma mensagem edificante, apenas perturbam limites do humano, ou de um gesto, concluído para sempre. Terríveis em sua incompletude onde promessas de felicidade, sentença de uma agonia infinda são destruídas, ou enfrentadas (BAPTISTA, 2018, p. 179-180).

A bestialidade de Hushpuppy acende em nós a fagulha desejante do devir-criança, última metamorfose do espírito (NIETZSCHE, 1883/2011), do infantilar uma revolta prática, brincar, jogar com os valores do nosso tempo, arriscar transvalorar. Bordamos este texto por meio desta névoa, tomando o sul como (nosso) norte, ali quando ainda se chora, quando ainda se revolta, quando ainda...

os dentes afiados da vida preferem a carne na mais tenra infância

quando as mordidas doem mais a deixam cicatrizes indeléveis quando o sabor da carne 
"os dentes afiados da vida preferem a carne na mais tenra infância": etnocartografar com olhos de besta

ainda não foi estragado pela salmoura do dia a dia

é quando ainda se chora

é quando

ainda se revolta

é quando

ainda

(LEMINSKI, 2013, p. 19).

\section{referências}

AGAMBEN, Giorgio. Infância e história: destruição da experiência e origem da história. Belo Horizonte: Editora UFMG, 2005.

BALESTRIN, Patrícia; SOARES, Rosângela. "Etnografia de tela": uma proposta metodológica. In: MEYER, Dagmar Estermann; PARAÍSO, Marlucy Alves (org.). Metodologias de pesquisas pós-críticas na educação. Belo Horizonte: Mazza Edições, 2012, p. 87-110.

BALESTRIN, Patrícia. Le fate ignoranti: a sexualidade levada a sério. Bagoas-Estudos gays: gêneros e sexualidades, v. 4, n. 10, 2013. Disponível em: $<$ https://periodicos.ufrn.br/bagoas/article/view/5376 >. Acesso em: 13 jan. 2019.

BAPTISTA, Luis Antonio dos Santos. Ética e barbárie de um gesto: a fragilidade servil da infância. In: RODRIGUES, Alessandro (org.). Crianças em dissidências: narrativas desobedientes da infância. Salvador: Editora Devires, 2018, p. 167184.

BEASTS OF THE SOUTHERN WILD. Diretor: Benh Zeitlin. 2012. Fox Pictures. DVD (93 minutos).

CASTRO, Eduardo Viveiros de. Metafísicas canibais: elementos para uma antropologia pós-estrutural. São Paulo: Ubu Editora, n-1 edições, 2018.

CORAZZA, Sandra Mara. Des-ilusão tem futuro?: artistagem da infância. In: COLOQUIO DO LEPSI IP/FE-USP, 4., 2002, São Paulo. Anais eletrônicos... Disponível em:<http://www.proceedings.scielo.br/scielo.php?script=sci_arttext\&pid=MS C0000000032002000400036\&lng=pt\&nrm=iso >. Acesso em: 27 jan. 2020.

. Artistagens: filosofia da diferença e educação. Belo Horizonte: Autêntica, 2006.

DELEUZE, Gilles. Que és un dispositivo?. In: CANGUILHEM, Georges (org.). Michel Foucault, filósofo. Barcelona: Gedisa Editorial, 1990, p. 155-161.

Três questões sobre seis vezes dois. In: _. Conversações. Rio de Janeiro: Ed. 34, 1992.

Cinema 2: a imagem-tempo. 1. ed. São Paulo: Brasiliense, 2005.

DELEUZE, Gilles.; GUATTARI, Félix. Mil Platôs: capitalismo e esquizofrenia. São Paulo: Editora 34, 1995. v. 2.

ELIAS, Norbert. A Solidão dos Moribundos: seguido de Envelhecer e Morrer. Rio de Janeiro: Zahar, 2001.

FERNANDES, Cleudemar. Discurso e produção de subjetividade em Michel Foucault. LEDIF, v. 2, n. 1, p. 1-19, 2011. Disponível em: <http:/ / pablo.deassis.net.br/wpcontent/uploads/61106619-Discurso-e-producao-de-subjetividade-em-MichelFoucault.pdf>. Acesso em: 12 de fev. de 2018.

HARAWAY, Donna Jeanne. Manifesto ciborgue: ciência, tecnologia e feminismosocialista no final do século XX. In: HARAWAY, Donna Jeanne.; KUNZRU, Hari; SILVA, Tomás Tadeu (org.). Antropologia do ciborgue: as vertigens do pós- 
marcos r. de melo; michele de f. faria de vasconcelos; edson augusto de souza neto

humano. Belo Horizonte: Autêntica, 2009, p. 33-118.

JARDS MACALÉ. Pacto de sangue. Besta fera. Disponível em: $<$ https://open.spotify.com/album/0fKrTiEu3rfpvmjduYvyE0?highlight=spotif y:track:2eXhEkBSTzKkpJpPNf0fDd>. Acesso em: 13 de jul. de 2019.

KASTRUP, Virgínia, et al. O funcionamento da atenção no trabalho do cartógrafo. Psicologia E sociedade, v. 19, n. 1, p. 15-22, 2007.

KASTRUP, Virgínia. O devir-criança e a cognição contemporânea. Psicologia: reflexão e crítica, v. 13, n. 3, p. 373-382, 2000.

KOHAN, Walter. Infância, estrangeiridade e ignorância: ensaios de filosofia e educação. Belo Horizonte: Autêntica, 2007.

LARROSA, Jorge. O enigma da infância. In: _. Pegadogia Profana: danças, piruetas e mascarados. Belo Horizonte: Autêntica, 2009, p. 183-198.

LEMINSKI, Paulo. Toda poesia. São Paulo: Companhia das Letras, 2013.

LOBO, Lilia Ferreira. Os infames da história: pobres, escravos e deficientes no Brasil. Rio de Janeiro: Lamparina, 2015.

NIETZSCHE, Friedrich. Assim falou Zaratustra. Editora Companhia das Letras, $1883 / 2011$.

NIEZTSCHE, Friedrich. Além do bem e do mal: prelúdio a uma filosofia do futuro. Porto Alegre: L\&PM, 1886/2008.

OKINAWA. Diretor: Leigh Jason. 1952. Columbia Pictures. DVD. (63 minutos).

PASSOS, Eduardo; KASTRUP, Virgínia; ESCÓSSIA, Liliana (orgs.). Pistas do método da cartografia: Pesquisa-intervenção e produção de subjetividade. Porto Alegre: Sulina, 2015.

PELBART, Peter Pál. Vida e morte em contexto de dominação biopolítica. Instituto de Estudos Avançados da Universidade de São Paulo. São Paulo: IEA, 2008. Disponível em:

<http://www.iea.usp.br/publicacoes/textos/ pelbartdominacaobiopolitica.pdf $>$. Acesso em: 13 de jun. de 2019.

PEIRANO, Mariza. A favor da etnografia. Rio de Janeiro: Relume-Dumará, 1995. Disponível

em:

<http://www.marizapeirano.com.br/textos/a_favor_da_etnografia.doc>.

Acesso em: 28 de ago. de 2020.

RIAL, Carmem Silva. RIAL, Carmen. Antropologia e mídia: breve panorama das teorias de comunicação. Antropologia em Primeira Mão, vol.9, n. 74, 2004, p.4-74.

ROLNIK, Suely. A hora da micropolítica (série Pandemia). São Paulo: Edições n-1, 2016.

ROLNIK, Suely. Cartografia sentimental: transformações contemporâneas do desejo. Porto Alegre: Sulina/Editora UFRGS, 2006.

SOUZA NETO, Edson Augusto; SANTOS, Anna Paula Silva; SANTOS, Geovanna Pirillo Canevalle dos; VASCONCELOS, Michele de Freitas Faria de. Balbuciando infâncias por meio da etnocartografia de tela. In: SILVA, Renato Izidoro da; NOGUEIRA, Adriana Dantas; FRANÇA, Lilian Cristina Monteiro (orgs.). Cinema e interdisciplinaridade: convergências, gêneros, discursos. 1. ed., vol. 3. Aracaju: Criação Editora, 2019. cap. 10, pp. 197-220.

VASCONCELOS, Michele de Freitas Faria de; MELO, Marcos Ribeiro de; OLIVEIRA, Roselusia Teresa de Morais. Imagens, narrativas, culturas infantis em "Abril despedaçado": tateando um modo de olhar. Revista Tempos e Espaços em Educação, v. 10, n. 21, p. 67-76, 2017. Disponível em: <https://seer.ufs.br/index.php/revtee/article/view/6333>. Acesso em $10 \mathrm{de}$ dez. de 2019.

VASCONCELOS, Michele de Freitas Faria; MELO, Marcos Ribeiro; SOUZA NETO, Edson Augusto. Etnocartografar com olhos rebeldes: infantilando imagens com "A Culpa é do Fidel". Interdisciplinar - Revista de Estudos em Lingua e Literatura, 
"os dentes afiados da vida preferem a carne na mais tenra infância": etnocartografar com olhos de besta

v. 29, $\quad 2018.0, \quad$ Disponível em: <https:// seer.ufs.br/index.php/interdisciplinar/article/view/9633>. Acesso em: 13 jan. 2019.

VICENTE, Bruna Gabriela Correia; SILVA, Débora Cristina Santos e. A cartografia de Deleuze e Guattari como metodologia de pesquisa. IN: IV Congresso de Ensino, Pesquisa e Extensão da UEG. 2018, Anápolis. Anais. Disponível em:< https://www.anais.ueg.br/ >. Acesso em 13 jan. 2019.

recebido em: 31.01 .2020

aprovado em: 03.09.2020 